\title{
Schistosomiasis mansoni: Follow-up of Control Program Based on Parasitologic and Serologic Methods in a Brazilian Community of Low Endemicity
}

\author{
Lanny Cristina Burlandy-Soares/+ , Luiz Cândido de Souza Dias, \\ Hermínia Yohko Kanamura***, Edward José de Oliveira**, Ricardo Mario Ciaravolo***
}

Departamento de Patologia Clínica, Faculdade de Ciências Médicas, Universidade Estadual de Campinas, Cidade Universitária

"Zeferino Vaz", Caixa Postal 6111, 13083-970 Campinas, SP, Brasil *Departamento de Biologia, Universidade de Taubaté, Taubaté, SP, Brasil **Faculdade de Ciências Farmacêuticas, Universidade de São Paulo, São Paulo, SP, Brasil

***Superintendência de Controle de Endemias, São Paulo, SP, Brasil

\begin{abstract}
A field survey on schistosomiais was carried out in 1998, in the municipality of Pedro de Toledo, a low endemic area in the state of São Paulo, Brazil. According to the parasitologic Kato-Katz method, the prevalence rate was $1.6 \%$, with an infection intensity of 40.9 eggs per gram of stool. By the immunofluorescence test (IFT) for detection of $\operatorname{Ig} G$ and IgM antibodies in the serum, IgG-IFT and IgM-IFT, respectively, prevalence indices of $33.2 \%$ and $33.5 \%$ were observed. To assess the impact of the schistosomiasis control program in the area, parasitologic and serologic data obtained in 1998, analyzed according to the age, sex, and residence zone, were compared to previous data obtained in a epidemiologic study carried out in 1980, when prevalence indices were of $22.8 \%$ and $55.5 \%$, respectively by Kato-Katz and IgG-IFT. A significant fall of the prevalence was observed, indicating that the control measures were effective. Nonetheless, residual transmission was observed, demonstrating the need for a joint effort to include new approaches for better understanding the real situation and improving the control of the disease in low endemic areas.
\end{abstract}

Key words: Schistosoma mansoni - control - low endemic area - seroepidemiology - São Paulo - Brazil

Schistosomiasis is an important global problem. It comes second to malaria as an important tropical disease with socioeconomic repercussion. It is endemic in 74 countries, occurring in Africa, the Middle East, South America, the Caribbean, Philippines, and Southeast Asia. Approximately 200 million individuals in the world are infected with schistosomiasis and 600 million are exposed to the risk of infection (WHO 1993). In Brazil, the extensive endemic area along with its overtly expansive character makes schistosomiasis a very relevant disease in the present public health panorama. It is believed that there are at least 2.5 million schistosomiasis carriers and about 25 million individuals exposed to the risk of contracting the infection (Passos \& Amaral 1998).

The control of this parasitosis in the state of São Paulo began in 1968 with the creation of Cacesq (Campaign for Combating Schistosomiasis). Since the seventies, Sucen (Superintendence for Control of Endemic Diseases of the Health Department of São Paulo State Government) has been conducting a control program in all regions con-

Financial support: CNPq and Fapesp (Proc 97/13904-0) This study received the approval of the Committee for Ethics in Research of the Faculty of Medical Sciences, Unicamp, Campinas, SP, Brazil, Process 190/99.

${ }^{+}$Corresponding author. Fax: +55-19-3858.1460. E-mail: lannysoares@hotmail.com

Received 3 October 2002

Accepted 13 Auguts 2003 sidered as important transmission areas in São Paulo: Valley of Paraíba do Sul River, Valley of Ribeira do Iguape River, Santos and south coastal region, Basin of Paranapanema River, and the metropolitan areas of municipalities of São Paulo and Campinas (Dias et al. 1992b).

Due to its epidemiological characteristics, the endemic areas in the state of São Paulo are designated as areas of low transmission, with prevalence indices lower than $15 \%$. In these areas the infected individuals use to show low intensity infection, eliminating less than 100 eggs per gram (epg), without clinical symptoms that are compatible with the disease (Dias et al. 1992b). Various authors have shown that in such areas, where individuals use to have reduced egg counts, the sensitivity of the parasitologic methods, usually applied in population surveys, is flawed when compared to the serologic methods (Dias et al. 1992b, De Vlas \& Gryscels 1992, Kanamura et al. 1998). There are various studies that assess the potential of different immunodiagnostic methods in populations (Deelder \& Kornelis 1981, Dias et al. 1992b, Noya et al. 1999). The immunofluorescence test (IFT) is a serological technique successfully applied as diagnostic tool in epidemiologic studies of schistosomiasis mansoni, in the state of São Paulo (Kanamura et al. 1998).

Schistosomiasis in São Paulo was first described, in 1953, in the region of Valley of Ribeira do Iguape River, in Itariri, a neighboring municipality of Pedro de Toledo, where this study was conducted. Despite control measures, the prevalence rate in Pedro de Toledo rose from $4 \%$ in 1970 to $12 \%$ in 1978 , motivating the intensification of control measures. These control 
activities started by Sucen in 1980, with the collaboration of researchers from the State University of Campinas (Unicamp), and the University of São Paulo (USP) (Dias et al. 1992a, b).

The 1980 survey involved stool examinations of approximately 4500 individuals and a prevalence index of $22.8 \%$, with an infection intensity of $55.5 \mathrm{epg}$, was demonstrated by Kato-Katz method (Dias et al. 1989). At the same time, prevalence indices of $55.5 \%$ and $51.8 \%$ were detected, respectively by immunofluorescence test for IgG antibodies (IgG-IFT) and intradermal reaction. The true prevalence of schistosomiasis in the municipality was estimated as $44.3 \%$, according to a probabilistic model for correction of prevalence data through the application of sensitivity and specificity indices obtained from previously published papers (Dias et al. 1992a).

Since 1980, the prevalence indices in Pedro de Toledo fell sharply as a result of the established control program. In 1987, the parasitological prevalence was 4.8\% (Dias et al. 1992b), and between 1992 and 1998 prevalence data determined by the Kato-Katz parasitologic method revealed indices around 2\% (Marçal Jr et al. 1999), suggesting the effectiveness of the control program. Nonetheless, an unknown number of individuals with a low parasitic load have probably been responsible for the maintenance of Schistosoma mansoni transmission, demonstrating the difficulty in controlling or eradicating endemicity when a significant percentage of infected individuals go undetected by the stool examinations. This underscores the importance of the serologic methods, in population studies, for obtaining prevalence rates, possibly closer to the real situation.

The purpose of this study is to assess the effectiveness of the control program implemented in Pedro de Toledo, comparing the results of the parasitologic and serologic methods obtained in 1998, with the ones observed in 1980, 18 years before the present seroepidemiological study.

\section{MATERIALS AND METHODS}

Description of the population and the region - This study was conducted in Pedro de Toledo, municipality localized in the Valley of Ribeira do Iguape River, with an estimated population of 7668 inhabitants (Seade 1998), and 5500 individuals of which living in areas exposed to the risk of schistosomiasis mansoni. This region has been characterized as an area of low endemicity in the state of São Paulo (Dias et al. 1989, 1992b). Approximately 15\% of the individuals of both sexes, various age groups, residents in rural and urban areas of the municipality, exposed to the risk of infection by $S$. mansoni, were randomly selected during the second semester of 1998 . The study group consisted of clinical samples from 894 individuals, being 749 stool and 591 blood samples obtained from finger pricks. It was also included a control group, without schistosomiasis, which was composed by 50 individuals of both sexes and various ages, some of them infected with parasitic species other than S. mansoni. They were from São Lourenço, a locality of Pedro de Toledo considered as non-endemic for schistosomiasis, and they provided 37 stool samples and 50 blood samples.
Clinical samples - The stools were collected in previously supplied recipients, one sample from each individual. The blood samples obtained from the finger pricks were collected on strips of Whatman ${ }^{\circledR} \mathrm{nr} 3$ filter paper $(1 \mathrm{~cm}$ wide and $10 \mathrm{~cm}$ long), dried at room temperature and stored in plastic bags at $-20^{\circ} \mathrm{C}$. The dried blood was eluted from the filter paper by immersing an area of approximately $1 \mathrm{~cm}^{2}$ in $330 \mu 1$ of PBS (phosphatebuffered solution, $0.01 \mathrm{M}, \mathrm{pH} 7.2$ ), and incubating for $18 \mathrm{~h}$ at $4^{\circ} \mathrm{C}$. The relative serum dilution, after elution and removal of the filter paper, was estimated to be 1:20 (Ferreira \& Carvalho 1982), and used for the IgG-IFT and IgMIFT (Silva et al. 1998).

Stool examination - The Kato-Katz method was used for parasitological examination, preparing three slides for each stool sample; S. mansoni egg counts were expressed in epg, using the arithmetic mean of egg counts obtained from three slides, multiplied by 24 (Katz et al. 1972). The intensity of infection in the area was estimated by the geometric mean of the S. mansoni egg counts (epg) found among the infected individuals. A commercial system, Coprotest ${ }^{\circledR}$ (Cerqueira 1988), was also used to examine the stool samples of the control group.

Immunofluorescence test for detection of $\operatorname{Ig} G$ and $\operatorname{IgM}$ antibodies (IgG-IFT, IgM-IFT) - The IgG-IFT on frozen sections of worms included in Tissue-Tek ${ }^{\circledR}$ (Miles Scientific, Indiana, US) was used to examine the eluates, in duplicate, as already described (Dias et al. 1992b). The immunofluorescence test for detection of IgM antibodies (IgM-IFT) against gut-associated antigens was performed on paraffin sections of $S$. mansoni worms treated with Rossman's solution, as described (Silva et al. 1992). The anti-human IgG and IgM fluorescent conjugates (Biolab, RJ, Brazil) were utilized according to their optimum titers, determined by block titration against positive and negative control sera. The slides were read at an Olympus BX-FLA fluorescent microscope equipped with a $100 \mathrm{~W}$ mercury lamp and an excitation filter BP 450-480 with a $100 \mathrm{X}$ magnifying power. The sample were defined as positive for IgG-IFT when presented fluorescence in the parenchyma and/or gut of the worms, and for IgM-IFT, when presented fluorescence in the gut of the worms.

Statistical analysis - The analysis of prevalence indices and the determination of $95 \%$ confidence interval to compare the data obtained in the present study with the ones obtained in 1998 were done using the statistical package of EPIINFO (Dean et al. 1995).

\section{RESULTS}

The S. mansoni parasitologic and serologic prevalence indices obtained in the present study were sumarized on the Table.

In 1998, the Kato-Katz method was used to examine 749 stool samples and revealed 284 individuals (37.9\%) infected by different helminth species, with a higher prevalence of Ascaris lumbricoides (23.2\%), followed by Trichuris trichiura (12.9\%). Among the 12 individuals infected by S. mansoni (1.6\%), nine (75\%) presented light infection $(<100 \mathrm{epg})$, two $(16.7 \%)$ moderate infection $(100-$ $400 \mathrm{epg}$ ) and only one (8.3\%) intense infection (> 400 epg), according to the classification of WHO (1993). The 
TABLE

Schistosoma mansoni prevalence indices by the parasitologic (Kato-Katz or Coprotest $\left.{ }^{\circledR}\right)$ and serologic (IgG-IFT and IgM-IFT) diagnostic methods in the study and control groups of the municipality of Pedro de Toledo, SP, Brazil, in 1998

\begin{tabular}{|c|c|c|c|c|c|c|}
\hline & \multicolumn{6}{|c|}{ Number and percentage of $S$. mansoni positive individuals } \\
\hline & \multicolumn{3}{|c|}{ Study group } & \multicolumn{3}{|c|}{ Control group } \\
\hline & Total & Positives & $\%$ & Total & Positives & $\%$ \\
\hline Kato-Katz & 749 & 12 & $1.6(0.9-2.9)$ & - & - & - \\
\hline Coprotest & - & - & - & 37 & 0 & 0 \\
\hline IgG-IFT & 591 & 196 & $33.2(29.4-37.1)$ & 50 & 2 & $4.0(0.70-14.8)$ \\
\hline IgM-IFT & 591 & 198 & $33.5(29.7-37.5)$ & 50 & 1 & $2.0(0.10-12.0)$ \\
\hline IgG/IgM-IFT & 591 & 176 & $29.8(26.2-33.7)$ & 50 & 1 & $2.0(0.10-12.0)$ \\
\hline
\end{tabular}

Study group: 894 individuals corresponding to about $12 \%$ of population from Pedro de Toledo, exposed to the risk of infection by S. mansoni; Control group: 50 individuals living in an area of Pedro de Toledo non-endemic for schistosomiasis; CI: 95\% confidence interval; Total: number of samples submitted to each diagnostic method; Positives: number of samples classified as reagent in each diagnostic method.

geometric mean of S. mansoni infection intensity in Pedro de Toledo, in 1998, was 40.9 epg. A total of 591 blood samples were submitted to IgG-IFT, giving a serologic prevalence of $33.2 \%$, with $95 \%$ confidence interval (CI) of 29.2-37.1. The blood samples were also submitted to IgMIFT, revealing a prevalence of $33.5 \%$ (CI: 29.7-37.5) for IgM antibodies against $S$. mansoni gut associated antigens. For both serological tests, the 25-29 (44.7\% CI: 30.5-59.8) age group was the highest prevalence group (Fig. 1). Positive results for IgG-IFT and IgM-IFT, simultaneously, were obtained in $29.8 \%$ (CI: 26.2-33.7) of the individuals living in areas at risk of $S$. mansoni infection in Pedro de Toledo, with higher prevalence for the rural (32.3\%, CI: $28-37.5)$ than the urban (24.6\%, CI: $18.9-31.1)$ zone and male (26.7\%, CI: $21.9-32)$ than female (33.3\%, CI: 27.9 -39.3) group (Fig. 2). In this study, $63.3 \%$ of the 894 participants were from rural zone. In this zone the schistosomiasis prevalence was $35.4 \%$ (30.7-40.4) by IgGIFT and $35.1 \%$ (CI: 30.4-40.2) by IgM-IFT (Fig. 2). These data showed to be higher than the prevalence in the urban zone, 28.9\% (CI: 22.4-35.7) and 30.4 (CI: 24.3-37.3) respectively for $\mathrm{IgG}$ and $\mathrm{IgM}$, although not statistically

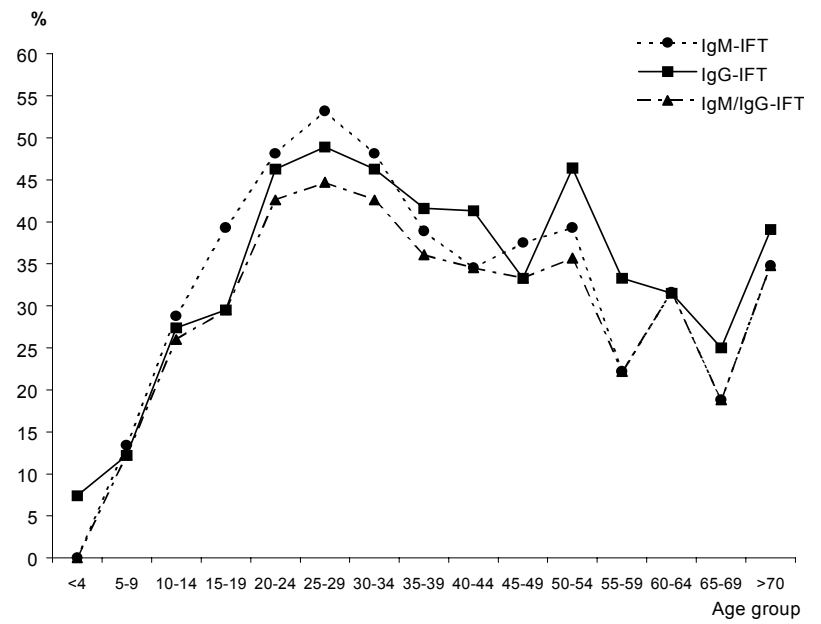

Fig. 1: prevalence rates of schistosomiasis mansoni by immunofluorescence test (IgG-IF, IgM-IFT), in 1998, according to age group, in 581 inhabitants from municipality of Pedro de Toledo, São Paulo. significant (Fig. 2). The data also showed that among the $\mathrm{IgG} / \mathrm{IgM}$ positive individuals, $73.9 \%$ were born in the state of São Paulo, the majority being from the region of the Valley of Ribeira do Iguape River. Nevertheless, the serological positivity for $\mathrm{IgG} / \mathrm{IgM}$ were higher for the individuals who came from other states (38.3\%, CI: 29.7 47.7) than the ones who was born in the state of São Paulo (27.6\%, CI: 23.7-31.9\%) (Fig. 2).

With relation to the control group, the 37 individuals who were submitted to the Coprotest ${ }^{\circledR}$ method were negative for $S$. mansoni eggs, but other helminth species were observed in 10 individuals (27\%). The positivity for
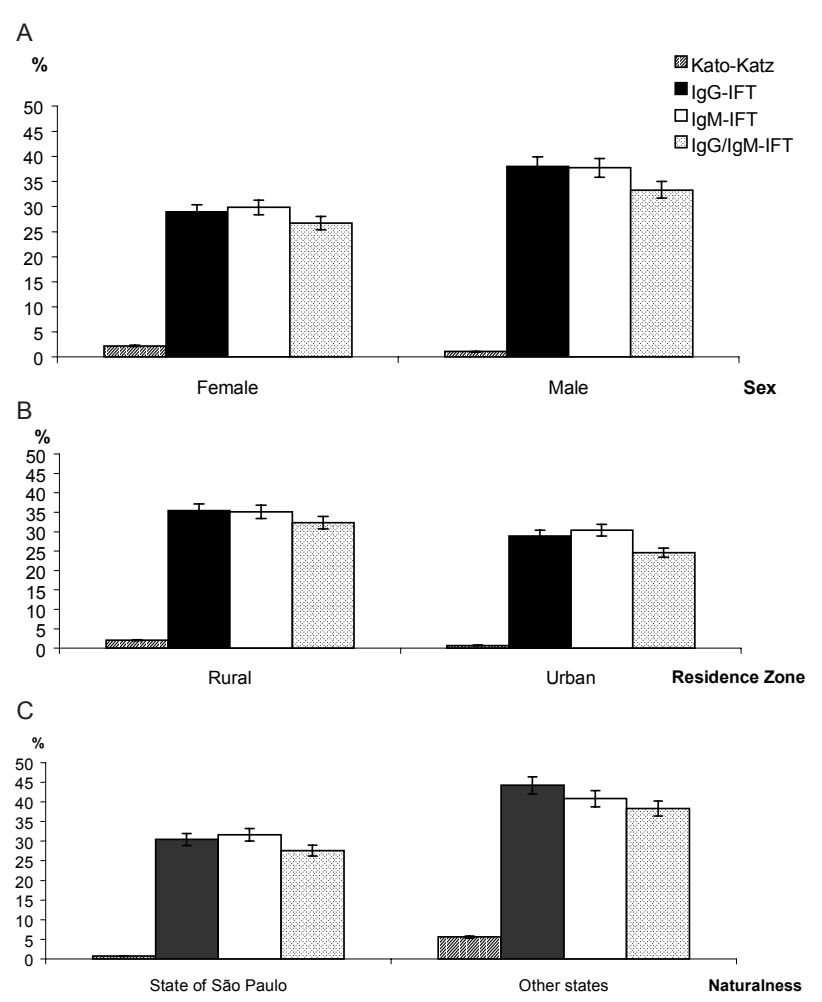

Fig. 2: prevalence rates of schistosomiasis mansoni by immunofluorescence test (IFT-IgG, IFT-IgM) and Kato-Katz method, in 1998, according to sex, residence zone, and naturalness, in municipality of Pedro de Toledo, São Paulo, Brazil. 
stool parasitological examination, including protozoa and helminth species, was $32.4 \%$ (CI: 18.6- 49.9\%). All the 50 individuals of this group provided blood samples for the serologic tests. IgG-IFT was positive for two individuals and IgM-IFT for one, giving positivity rates of $4 \%$ and $2 \%$, respectively. These data suggest good specificity of the serologic tests applied in this study.

When the parasitologic and serologic data obtained in this study (1998) were compared with those obtained in1980 (Hoshino-Shimizu et al. 1986), an accentuated fall was observed in the prevalence indices. The prevalence by Kato-Katz method fell from $22.8 \%$ (CI: 21.7-24.1) in 1980 to $1.6 \%$ (CI: $0.9-2.9$ ) in 1998 . The serologic prevalence by IgG-IFT which was $55.5 \%$ (CI: 53.5-57.5) in 1980 fell to $33.2 \%$ (CI: 29.4-37.1) in 1998 (Fig. 3). Analyzing the 95\% confidence interval of the prevalence indices, these differences were statistically significant. According to the age group, it was observed tendency for dislocation of the higher prevalence group from 10-14 age group, in 1980, to an older 25-29 group, in 1998 (Fig. 4). According to the zone of residence (Fig. 5), the parasitologic and serologic prevalence indices showed to be higher in rural than urban zone in both surveys. The differences were not statistically significant in 1998, but in 1980 parasitologic prevalence rates were significantly higher for the rural $25.5 \%$ (CI: 23.8 -27.3 ) than the urban zone $20.2 \%$ (CI: 18.6-21.9). The same was observed for the serologic prevalence rates, significantly higher for the rural $(65.4 \%$; CI: 62.8-67.9) than the urban zone (44.1\%; CI: 40.6-46.5) (Fig. 5). In 1998, among the Kato-Katz positive individuals, $83 \%(10 / 12)$ lived in the rural zone, while in 1980 this percentage was $56 \%(605 / 1083)$. For the IFT-IgG, 70\% (137/196) of the individuals with a positive serology lived in the rural area in 1998 and this percentage was $65 \%(894 / 1386)$ in 1980. In the rural zone, parasitologic prevalence that was $25.5 \%$ in 1980 fell to $2.1 \%$ in 1998 , and serologic prevalence fell from $65.4 \%$ to $35.4 \%$. In the urban zone, parasitologic prevalence that was $20.2 \%$ in 1980 fell to $0.7 \%$ in 1998 , and serologic prevalence fell from $44.1 \%$ to $28.9 \%$ (Fig. 5). With relation to the sex, in 1980, parasitologic prevalence

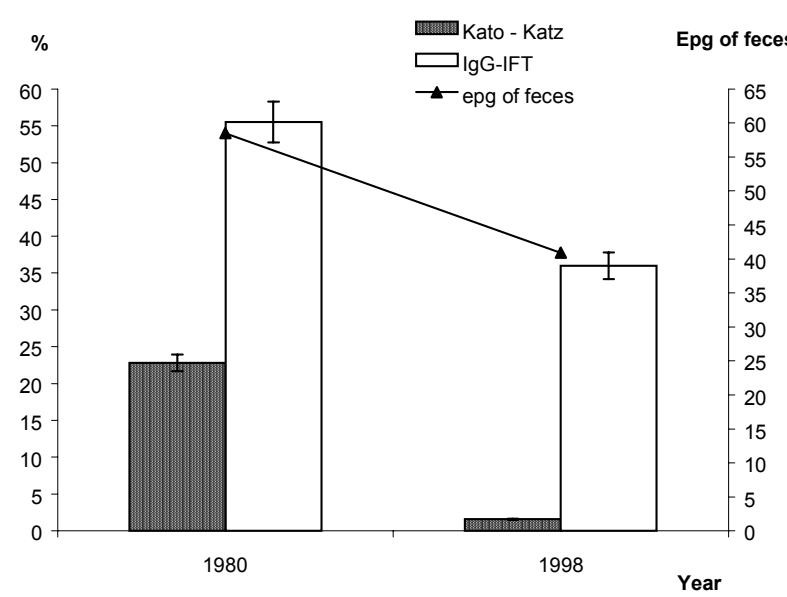

Fig. 3: prevalence rates of schistosomiasis mansoni by immunofluorescence test (IgG-IFT), Kato-Katz method and intensity of infection (epg - geometric mean of the number the eggs per gram of feces), in 1980 and 1998, in municipality of Pedro de Toledo, São Paulo, Brazil. was statistically higher for the male (30.7\%, CI: $28.9-32.6)$ than female (17.3\%, CI: 15.8-19.0) group, and in 1998 was the opposite, higher in the female group, although the difference was not significant. The serologic prevalence indices were significantly higher for the male group $(60.7 \%$, CI: 57.9 - 63.4) than female (50.5\%, CI: 47.8-53.3) in 1980. The prevalence was also higher in the male group in 1998, but with no statistic difference (Fig. 5).

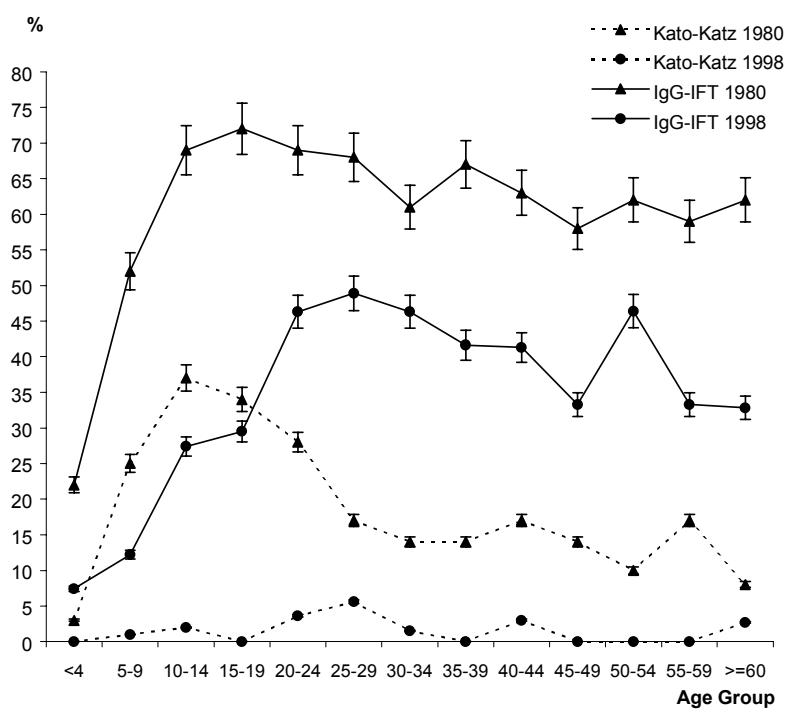

Fig. 4: prevalence rates of schistosomiasis mansoni by immunofluorescence test (IgG-IFT, IgM-IFT) and Katz method, in 1980 and 1998, according to age group, in municipality of Pedro de Toledo, São Paulo, Brazil.

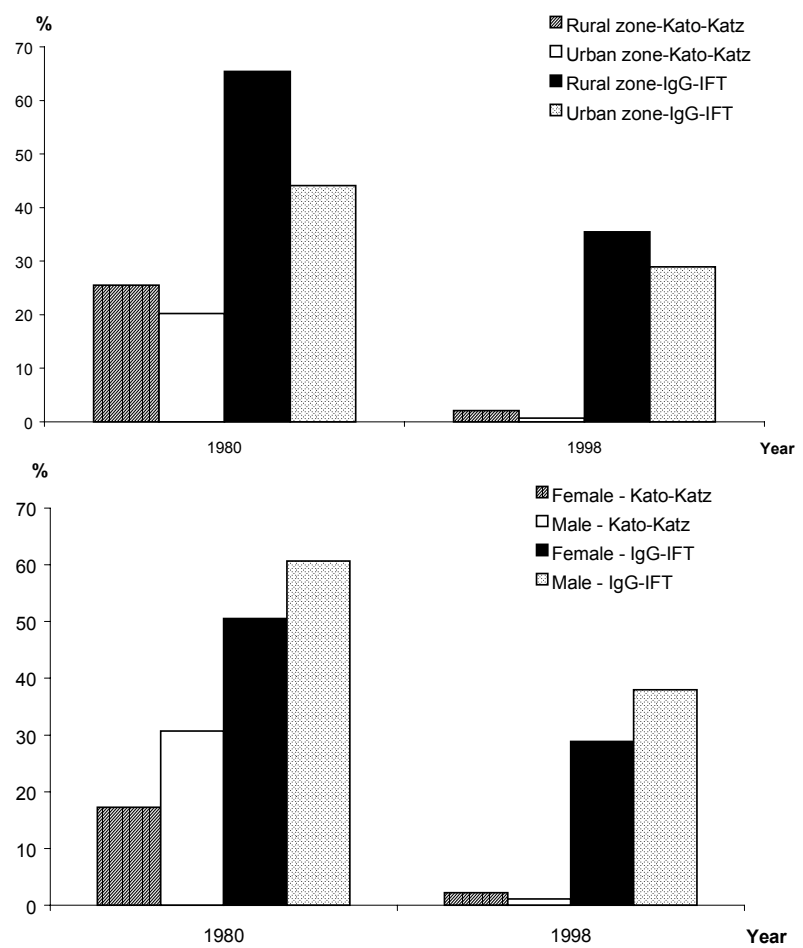

Fig. 5: prevalence rates of schistosomiasis mansoni by immunofluorescence test (IgG-IFT) and Kato-Katz method, according to zone (rural and urban) and sex (female and male), in 1980 and 1998, in municipality of Pedro de Toledo, São Paulo, Brazil. 


\section{DISCUSSION}

Diagnosis of schistosomiasis is mainly based on stool examinations; which is reliable in areas of high and medium endemicity, where the intensity of infection is high. The characteristics of the $S$. mansoni transmission in the state of São Paulo are different from other high endemic areas, especially from the Northeast areas of Brazil. The schistosomiasis endemic areas in São Paulo are of low endemicity with parasitologic prevalence indices lower than $15 \%$. In these areas, the majority of the infected individuals does not present clinical symptomatology and use to excrete low number of $S$. mansoni eggs in the stool, less than 100 epg (Dias et al. 1992b).

The epidemiological studies that provide information for implementing control measures in our country are mainly based on parasitologic techniques. The Kato-Katz method is practically the only parasitologic method utilized for the diagnosis of schistosomiasis because of its simplicity and low cost. However, low infections may be overlooked due to false-negative results, even though two or more slides are examined (De Vlas \& Gryseels 1992). Parasitologic methods have poor sensitivity in individuals with small number of eggs in the stools. It underestimates the prevalence in areas with low infection intensity, and also in populations living in endemic areas where the schistosomiasis control program was introduced, hampering a correct evaluation of the control strategies (Dias et al. 1992a, b, Noya et al. 1999).

In order to successfully assessing control programs for schistosomiasis mansoni, it is of fundamental importance the use of diagnostic tests with adequate indices of specificity and sensitivity. Under certain conditions, some serologic tests can better estimate the real prevalence of this parasitosis than the classical stool exams (Noya et al. 1999). Techniques for detection of circulating antigens have not attained yet an acceptable degree of sensitivity for the diagnosis of individuals with low parasitic loads (El-Morshedy et al. 1996), but methodologies that detect specific antibodies have shown sensitivity indices close to $100 \%$ (Lima et al. 1996). The indirect immunofluorescence tests on worm paraffin (IgMIFT) or frozen sections (IgG-IFT) have presented satisfactory degrees of sensitivity and specificity for diagnosis of schistosomiasis (Kanamura et al. 1979, Deelder \& Kornelis 1981, Silva et al. 1992). Other methodologies such as the ELISA test may also be used as important diagnostic tool (Noya et al. 1999). Although the serologic techniques are very efficient, they do not constitute part of the diagnostic routine for schistosomiasis mansoni, and also they are not commonly used in epidemiologic studies in our country.

Pedro de Toledo, municipality where this study was carried out, is one of the areas with active transmission of schistosomiasis and carefully studied in the state of São Paulo ( Marçal Jr et al. 1991, Dias et al. 1989, 1992b). The parasitologic prevalence in 1970 was $4 \%$ and rose to $12 \%$ in 1978. An epidemiologic survey, with parasitologic and immunologic methods, was conducted in 1980, and than a control program was intensified, with emphasis on specific treatment of the infected patients, sanitary education and improvement of basic sanitation (Dias et al. 1992b). These measures are still being maintained.

In low endemic areas for schistosomiasis, serologic prevalence indices have shown to be 2 to 5 times higher than the parasitologic indices (Dias et al. 1989, Noya et al 1999). In Pedro de Toledo, in 1980, by the IgG-IFT the prevalence was $55.5 \%$, and by Kato-Katz method, it was $22.8 \%$, with an infection intensity of $58.5 \mathrm{epg}$. Than, the serologic prevalence was 2.6 times higher than the parasitologic prevalence. In this study, in 1998, the serologic prevalence by IgG-IFT was $33.2 \%$, which was 20 times higher than the parasitologic prevalence of $1.6 \%$, obtained by Kato-Katz method, with an infection intensity of 40.9 epg (Fig. 3).

It is known that a single stool examination does not satisfactorily detect individuals with less than $23 \mathrm{epg}$, which is the lowest limit for the sensitivity of the KatoKatz method (Noya et al. 1992). In our study group the geometric mean egg counts of nine individuals with light infections was $22.6 \mathrm{epg}$, so lower than the sensitivity of the Kato-Katz method. Two individuals showed moderate infection intensity, with geometric mean egg counts of $128 \mathrm{epg}$, and the last one, an intense infection with 856 epg. It is important to comment that this individual was a migrant from the Northeast area of Brazil, and the responsible for increasing the geometric mean of the egg positive individuals in the 1998 survey. These facts can partially explain the underestimated schistosomiasis prevalence data, when only three slides for fecal sample, one sample from each participant, were examined. In areas like Pedro de Toledo, with low endemicity, the geometric mean egg counts are probably lower if greater number of samples and/or slides could be examined.

An interesting observation was the dislocation of the highest prevalence group from a younger to an older age group. In 1980, the 15-19 age group showed to be the highest prevalence group, and in 1998, the highest seroprevalence group was composed by individuals of 25 to 29 years old (Fig. 4). The poor population used to swim and fish in the streams and lakes, since there were no other options of leisure in the region, raising the risk of schistosomiasis infection. Sanitary education was primarily directed to the schoolchildren and also involved the adults in a second step. It is probably due to the effectiveness of the control measures, the significant fall of prevalence observed for the 15-19 age group, composed by individuals who were born after beginning of the intensification of the control program.

The significant differences in the parasitologic and serologic prevalence rates between rural and urban zones observed in 1980, but not in 1998, might suggest urbanization of schistosomiasis. Schistosomiasis was originally considered a typically rural disease but, nowadays, S. mansoni transmission also occurs in the periphery of cities where the concentration of lower income class residents and poor sanitary conditions favor the installation of new foci (Katz \& Peixoto 2000).

Another aspect that must be better investigated is the high difference between serologic and parasitologic prevalence data observed in the area. The low diagnostic sensitivity of the parasitoliogic methods is undoubtedly 
one of the main factors. Other factor might be the presence of individuals who have developed immune response to $S$. mansoni antigens after exposition to cercaria, but without development of infection, or have been cured after chemotherapy and still present circulating antibodies. It is a well known fact that immediately after chemotherapy, the levels of specific antibodies rise stimulated by the death of the parasites and fall soon after. They may disappear within 6 to 12 months or after a period 5 years, depending on the technique and antigen used (Noya et al. 1992, Kanamura et al. 1997). Among 198 IgM positive residents in Pedro de Toledo, in 1998, 14 were identified as having been previously treated with oxamniquine. None of them presented S. mansoni eggs in the feces. The presence o circulating antibodies in 13 individuals, who were treated for more than 5 years, might suggest failure in the treatment, with maintenance of a low infection not detected for the parasitologic examination, re-exposure of these individuals to cercaria, without establishment of infection, or cross reactions because contact with other parasites. The occurrence of cross-reactions with antigens of other helminth species like Ascaris or Trichuris has not been observed with the control group in the present study, confirming the results obtained previous studies (Kanamura et al. 1998).

Although, in the 1998 survey, the majority of egg positive individuals were migrants from other states of Brazil, the persistence of active transmission in the studied area was evident, with the detection of four autochthonous cases (one child, two adults, and one elderly individual).

Transmission might be maintained due to inconstant and inadequate actions that do not cover the entire population because of low sensitivity of the diagnostic methods, flawed control measures, constant flux of migrants and the internal movement of individuals who are carriers.

In Brazil, schistosomiasis can be characterized as a zoonosis because some few mammalian species have the capacity of developing infection, permitting the parasite to complete its biological cycle in a natural environment. Previous publications have described that some rodents can participate in the $S$. mansoni cycle but are unable to maintain an infection independent of man (Dias et al. 1978). Studies should be conducted to investigate the participation of small wild rodents as an aggravating factor for maintenance of residual transmission in Pedro de Toledo.

This residual prevalence might also be due to the failure in the previous treatment. Chemotherapy is relevant with regard to prevention of morbidity and reduction of prevalence. Nevertheless, about 15 to $20 \%$ of the individuals who are treated continue eliminating eggs as a result of some live worms in the mesenteric veins (Dias et al. 1982). In this situation, the treatment prevents elevated parasitic loads but does not stop transmission. It is also known that $S$. mansoni can develop resistance to certain therapeutic drugs such as oxamniquine or praziquantel, especially when the parasitic population is under continuous pressure from schistosomicides (Bonesso-Sabadini \& Dias 2002).
Further studies are necessary to establish reliable diagnosis and chemotherapy criteria based on serologic methods, more adequate to epidemiological conditions of low endemic areas, such as Pedro de Toledo, where the use of parasitologic methods is demonstrated to be not completely appropriate.

The introduction of serologic methods in epidemiological studies, identifying potential infection sources, may contribute towards the reduction of residual transmission in Pedro de Toledo. This procedure could also be extended to other areas in the state of São Paulo with similar epidemiological characteristics or even be included in a national program for the control of schistosomiasis mansoni.

\section{REFERENCES}

Bonesso-Sabadini PI, Dias LCS 2002. Altered response of strain of Schistosoma mansoni to oxamniquine and praziquantel. Mem Inst Oswaldo Cruz, 97: 381-385.

Cerqueira FL 1988. Coprotest ${ }^{\circledR}$ : metodologia confiável para o exame parasitológico de fezes. Laes \& Laes 9: 5-12.

Dean AG, Dean JA, Colulombier D, Brendel KA, Smith DC, Burton AH, Dicker RC, Sullivan KM, Fargan RF, Arner TG 1995. Epi Info, version 6: a word processing database, and statistics program for public health on IBM-compatible microcomputer. Center of Disease Control on Prevention, Atlanta, GA, US.

Deelder AM, Kornelis D 1981. Immunodiagnosis of recently acquired $S$. mansoni infection. A comparation of various immunological techniques. Trop Geog Med 33: 36-41.

De Vlas SJ, Gryscels B 1992. Underestimation of Schistosoma mansoni prevalence. Parasitol Today 8: 274-277.

Dias LCS, Ávila-Pires FD, Pinto ACM 1978. Parasitological and ecological aspects of schistosomiasis mansoni in the valley of the Paraíba do Sul river (São Paulo State, Brazil) I. Natural infection of small mammals with Schistosoma mansoni. Trans R Soc Trop Med Hyg 72: 496-500.

Dias LCS, Kanamura HY, Hoshino-Shimizu S, Glasser CM, Carvalho JF, Silva LC 1992a. Field trials for immunodiagnosis with reference to Schistosoma mansoni. In NR Bergquist, Immunodiagnostic Approches in Schistosomiasis, John Wiley \& Sons, England, p. 39-47.

Dias LCS, Kawazoe U, Glasser CM, Hoshino-Shimizu S, Kanamura HY, Cordeiro JA, Guarata OF, Ishirata GJ 1989. Schistosomiasis mansoni in the municipality of Pedro de Toledo (São Paulo, Brazil) where the Biomphalaria tenagophila is the snail host: I. Prevalence in human population. Rev Inst Med Trop 31: 110 -118.

Dias LCS, Marçal Jr O, Glasser CM, Kanamura HY, Hotta LC 1992b. Control of schistosomiasis mansoni in a low transmission area. Mem Inst Oswaldo Cruz 87 (Suppl. IV): 233-239.

Dias LCS, Pedro RJ, Deberalini ER 1982. Use of PZQ in patients with schistosomiasis mansoni previously treated with OXA and/or hycantone: resistance of Schistosoma mansoni to schistosomicidal agents. Trans R Soc Trop Med Hyg 76: 652-659.

El-Morshedy H, Kinosien B, Barakat R, Omer E, Khamis N, Deelder AM, Phillips M 1996. Circulating anodic antigen for detection of Schistosoma mansoni infection in Egyptian patients. Am J Trop Med Hyg 54: 149-153.

Ferreira CS, Carvalho ME 1982. Padronização de uso de papelfiltro como suporte de material para reações sorológicas. Rev Bras Malariol 34: 82-86.

Hoshino-Shimizu S, Camargo MC, Kawada HYK, Silva LC, 
Dias LCS 1986. Aspectos sorológicos e soroepidemiológicos da esquistossomose mansônica. In FA Reis, I Faria, N Katz (eds), Modernos Conhecimentos sobre Esquistossomose Mansônica. Suplemento dos Anais de 1983 e 1984, Academia Mineira de Medicina, p. 67-89.

Kanamura HY, Dias LCS, Glasser CM, Silva RM, Patucci RMJ, Chiodelli SG, Addis DG 1998. Detection of IgM antibodies to Schistosoma mansoni gut-associated antigens for the study of the dynamics of schistosomiasis transmission in an endemic area with low worm burden. Rev Inst Med Trop São Paulo 40: 225-231.

Kanamura HY, Hoshino-Shimizu S, Camargo ME, Silva LC 1979. Class specific antibodies and fluorescent staining patterns in acute and chronic forms of schistosomiasis mansoni. Am J Trop Med Hyg 28: 242-248.

Kanamura HY, Hoshino-Shimizu S, Kimura RT, Matsumoto TK, Silva LC, Lima DMC, Abrantes-Lemos CP 1997. Decay of antibody isotypes against early developmental stages of Schistosoma mansoni after treatment of schistosomiasis patients. Rev Inst Med Trop São Paulo 39: 271-277.

Katz N, Peixoto SV 2000. Análise critica da estimativa do número de portadores de esquistossomose mansoni no Brasil. Rev Soc Bras Med Trop 33: 303-308.

Katz N, Chaves A, Pellegrino J 1972. A simple device for quantitative stool thick smear technique in schistosomiasis. Rev Inst Med Trop São Paulo 14: 397-4002.

Lima DM, Abrantes-Lemos CP, Hoshino-Shimizu S, Valli LCP, Kanamura HY, Da Silva LC, Vellosa AS 1996. Imunodiagnóstico da esquistossomose mansônica com baixa carga parasitária. Rev Soc Bras Med Trop 29: 145-152.

Marçal Jr O, Dias LCS, Kanamura HY, Soares LCB, Oliveira EJ
1999. Evaluation of a schistosomiasis mansoni control programme in an area of low endemicity, in Brazil. VII International Symposium on Schistosomiasis, Rio de Janeiro, p. 79.

Marçal Jr, Patucci RMJ, Dias LCS, Hotta LK, Etzel A 1991. Schistosomiasis mansoni in area of transmission. I. Impact of control measures. Rev Inst Med Trop São Paulo 33: 8390.

Noya BA, Balzan C, Artega C, Cesari I, Noya O 1999. The last fifteen years of schistosomiasis in Venezuela: features an evolution. Mem Inst Oswaldo Cruz 94: 136-146.

Noya BA, Spencer L, Noya O 1992. Pre-and post treatment immunodiagnostic evaluation in human schistosomiasis mansoni. Mem Inst Oswaldo Cruz 87 (Suppl. IV): 271-276.

Passos ADC, Amaral RS 1998. Esquistossomose mansônica; aspectos epidemiológicos e de controle. Rev Soc Bras Med Trop 31 (Supl. II): 61-74.

Seade-Fundação Sistema Estadual de Análise de Dados 1998. Anuário Estatístico do Estado de São Paulo.

Silva RM, Kanamura HY, Camargo E, Chiodelli SG, Nakamura PM, Gargioni C, Vellosa SAG, Antunes JLF 1998. A comparative study on IgG-ELISA, IgM-IFT and Kato-Katz methods for epidemiological purposes in a low endemic area for schistosomiasis. Mem Inst Oswaldo Cruz 93 (Suppl. I): 279-282.

Silva RM, Silva MIPG, Vellosa SAG, Kanamura HY 1992. Pesquisa de anticorpos IgM contra o tubo digestivo do verme para o diagnóstico da esquistossomose mansônica. Rev Bras Pat Clin 28: 39-42.

WHO-World Health Organization 1993. The Control of Schistosomiasis, Technical Report Series 830, Geneva, 86 pp. 